anaphase half the content of the metaphase. At the end of telophase, a new synthesis occurs. This doubles the content of each cell, so that each interphasic blastomere contains the same content as the whole preceding metaphase.

These observations permit the following conclusions. (1) Many authors, arguing from theory, have expressed the view that the deoxyribonucleic acid content of both gametes must be identical. The experimental evidence obtained from Sabellaria does not favour this view. (2) According to Boivin, Vendrely and Vendrely ${ }^{3}$ and others, the deoxy. ribonucleic acid content of the (diploid) somatic cells must always be twice that of the (haploid) gametes, or in cases of polyploidy a simple multiple of this value. The values found from Sabellaria are very different from the theoretical ratios $1: 2$, or $1: 4$, $1: 8$, etc. ; the ratio for spermatozoid to somatic cell (first blastomere) deoxyribonucleic acid is approximately $1: 12$, and that for mature egg to somatic cell is $1: 5 \cdot 5$. (3) After fertilization, a considerable synthesis of deoxyribonucleic acid occurs in the spermatozoid and in the mature egg; the content of the spermatozoid is multiplied approximately six times, that of the egg approximately by $2 \cdot 75$. (4) In the course of the first segmentation division, the synthesis of nucleic acid occurs during late telophase. This is in accordance with our earlier finding on the synthesis of nucleic acid in the multiplying somatic cells ${ }^{2,4}$.

Department of Embryology,

\section{J. Pasteels}

Department of Histology,

L. LISON

University of Brussels. Jan. 26.

${ }^{1}$ Lison, I., Acta Anatomica (Basel), 10, 333 (1950).

' Lison, I., and Pasteels, J., Arch. Biol., 62, 1 (1951).

${ }^{3}$ Vendrely, R., and Vendrely, C., Experientia, 5, 327 (1949).

- Pasteels, J., and Lison, L., Arch. Biol., 61, 445 (1950).

\section{Formation of Glycolaldehyde by Enzymic Scission of Pentoses}

Fischler and Boettner ${ }^{1}$ showed that pentoses can be split by alkali into glycolaldehyde and a triose. In the biochemical field, glycolaldehyde has been identified as a by-product in yeast fermentations, by Neuberg, who assumed that it arose via hydroxypyruvic acid.

Many micro-organisms of diverse types can attack one or more pentoses, and there is evidence that, when this occurs, the sugar is split into a triose and a molecule containing two carbon atoms $\mathrm{s}^{3-6}$. During the breakdown of pentoses by a Fusarium species, Wirth and Nord ${ }^{7}$ detected pyruvic acid in the metabolism solution and they assumed that the other scission product was glycolaldehyde. The suggestion that the latter substance is a product of the action of yeast on D-ribose-5-phosphate has been put forward by Dickens ${ }^{8}$. Glycolaldehyde has been isolated as its dimedone derivative, by Goepfert and Nord ${ }^{9}$, from cultures of Fusarium lini Bolley on a medium containing ethylene glycol as the only source of energy.

Kaushal and Walker ${ }^{10}$ showed that the oxidation of ethylene glycol by Acetobacter acetigenum similarly results in the formation of glycolaldehyde, which, in this case, was isolated as its $2: 4$-dinitrophenylosazone. Hitherto, however, the detection of glycolaldehyde during the utilization of pentoses or other sugars by micro-organisms has not been reported. We have now established the formation of glycolaldehyde by the action of Acetobacter acetigenum and related species upon the sugars $\mathrm{D}$-xylose and L-arabinose.

Samples taken daily from cultures of these organisms developing at $30^{\circ} \mathrm{C}$. upon media containing one or other of these pentoses as source of carbon showed, towards Fehling's solution, a reducing action which increased steadily to a maximum. At this stage addition of a solution of $2: 4$-dinitrophenylhydrazine in $2-N$ hydrochloric acid precipitated a red powder consisting of a mixture of substances. By fractionation with glacial acetic acid, a red compound which was almost insoluble in this solvent was isolated and was purified by crystallization from nitrobenzene and from chlorobenzene. It melted at $329^{\circ} \mathrm{C}$. alone, or in admixture with the 2:4-dinitrophenylosazone from a sample of authentic glycolaldehyde which had been prepared from ethylene glycol by the method of Fenton and Jackson ${ }^{11}$. On combustion, the compound from the cultures gave figures for $\mathrm{C}, \mathrm{H}$ and $\mathrm{N}$ in agreement with those calculated for the $2: 4$-dinitrophenylosazone of glycolaldehyde.
R. KAUSHAL
P. JoWETT
T. K. WALKER

Chemistry Department,

College of Technology, Manchester 1. Feb. 2 .

' Fischler, F., and Boettner, R., Z. physiol. Chem., 177, 264 (1928). ${ }^{2}$ Neuberg, C., and Rosenthal, P., Biochem. Z., B1, 171 (1914).

${ }^{8}$ Fred, E. B., Peterson, W. H., and Davennort, A., J. Biol. Chem., 39, 367 (1919).

${ }^{4}$ Fred, E. B., Peterson, W. H., and Davenport, A., J. Biol. Chem., 42, $188(1920)$ ${ }^{5}$ Challenger, F., Klein, L., and Walker, T. K., J. Chem. Soc., 1498

${ }^{6}$ Challenger, F., Klein, L., and Walker, T. K., J. Chem. Soc., 16 (1931). ${ }^{7}$ Wirth, J. C., and Nord, F. F., Arch. Biochem., 1, 143 (1942).

${ }^{3}$ Dickens, F., Biochem. J., 32, 1645 (1938).

${ }^{9}$ Goepfert, G. J,, and Nord, F. F., Arch. Biochem., 1, 289 (1942).

${ }^{10}$ Kaushal, R., and Walker, 'T. K., Nature, 160, 572 (1947).

${ }_{11}$ Fenton, H. J. H., and Jackson, H., J. Chem. Soc., 75, 3 (1899).

\section{Functional Survival of Fowl Spermatozoa after Freezing at $-79^{\circ} \mathrm{C}$.}

Shaffner, Henderson and Card reported that, in fowl semen to which lævulose had been added, about 30 per cent of the spermatozoa could be revived after freezing to $-79^{\circ}$ C. ${ }^{1}$. Some spermatozoa so treated apparently remained capable of fertilizing eggs, although the embryos died at a very early stage (10-15 hr.) of development ${ }^{2}$.

Recent work at this Institute has shown that, if fowl semen is diluted to contain 15-20 per cent glycerol, it can be frozen to $-79^{\circ} \mathrm{C}$. and thawed at $40^{\circ} \mathrm{C}$. without impairing the motility of the spermatozoa ${ }^{3}$. However, insemination into hens of semen containing more than 5 per cent glycerol, frozen or unfrozen, failed to result in fertile eggs. 2 per cent glycerol in the semen was the maximum concentration compatible with the rotention of full fertilizing power. Nevertheless, there was some indication that the very few spermatozoa which survived freezing in this concentration of glycerol remained functional ${ }^{4}$. 